Short communication

\title{
GENDER DIMORPHISM IN THE EXERCISE-NAÏVE MURINE SKELETAL MUSCLE PROTEOME
}

\author{
LAUREN ANN METSKAS ${ }^{1}$, MOHINI KULP ${ }^{2}$ \\ and STYLIANOS P. SCORDILIS ${ }^{1,2,3 *}$ \\ ${ }^{1}$ Biological Sciences, ${ }^{2}$ Center for Proteomics, ${ }^{3}$ Biochemistry, Smith College, \\ Northampton, MA, United States
}

\begin{abstract}
Skeletal muscle is a plastic tissue with known gender dimorphism, especially at the metabolic level. A proteomic comparison of male and female murine biceps brachii was undertaken, resolving an average of 600 protein spots of MW $15-150 \mathrm{kDa}$ and $\mathrm{pI} 5-8$. Twenty-six unique full-length proteins spanning 11 KOG groups demonstrated statistically significant $(\mathrm{p}<0.05)$ abundance differences between genders; the majority of these proteins have metabolic functions. Identified glycolytic enzymes demonstrated decreased abundance in females, while abundance differences in identified oxidative phosphorylation enzymes were specific to the proteins rather than to the functional group as a whole. Certain cytoskeletal and stress proteins showed specific expression differences, and all three phosphorylation states of creatine kinase showed significant decreased abundance in females. Expression differences were significant but many were subtle $(\leq 2$-fold), and known hormonally-regulated proteins were not identified. We conclude that while gender dimorphism is present in non-exercised murine skeletal muscle, the proteome comparison of male and female biceps brachii in exercise-naïve mice indicates subtle differences rather than a large or obviously hormonal dimorphism.
\end{abstract}

Key words: Gender, Muscle proteomics, Glycolysis, Creatine kinase

* Author for correspondence. e-mail: sscordil@smith.edu

Abbreviations used: CHAPS - 3-[(3-cholamidopropyl)dimethylammonio]-1-propanesulfonate hydrate; CID - collision-induced dissociation; CK - creatine kinase; GLUT glucose transporter; GRP - glucose-regulated protein; IPG - immobilized $\mathrm{pH}$ gradient; KOG - eukaryotic orthologous group; $\mathrm{M}_{\mathrm{r}}$ - apparent molecular weight; SDS - sodium dodecyl sulfate 


\section{INTRODUCTION}

Skeletal muscle is a plastic tissue, adapting in response to mechanical or metabolic challenges through alterations in substrate metabolism, cytoskeletal stability, and stress protein abundance and activation. In gender-controlled experiments, a recurring trend is dimorphism in the metabolic exercise response. Females typically have a higher percentage of body fat than their male counterparts [1], and depend upon those stores for energy more than males [2]. In a survey of gender-controlled respiratory exchange ratio studies, Tarnopolsky et al. showed a clear trend for greater lipid oxidation in female athletes both during exercise and at rest [3]. An assay of targeted mRNA's confirmed increased transcription of several genes related to fat metabolism [3]. While molecular indications of gender dimorphism in skeletal muscle are abundant, the most compelling and reproducible evidence of gender dimorphism in metabolism continues to be systemic and indirect, leaving many questions unanswered as to the exact mechanisms involved.

Most in vivo studies showing gender dimorphism in skeletal muscle protein expression do so in an increased-demand environment, typically exercise/ training or caloric restriction. Gender-controlled proteome comparisons following a repeated bout of downhill running in mice indicate expression changes in over 70 cytoskeletal, metabolic and stress proteins, and many of these proteins show gender dimorphism in the exercise response beyond one week post-exercise [4]. Because the male and female skeletal muscle proteomes show different adaptation in response to exercise, baseline studies in athletes may be biased toward a greater dimorphism than that of non-challenged muscle.

Of non-challenged muscle studies, two DNA microarray studies of skeletal muscle report conflicting results. Yoshioka et al. [5] showed increased transcription of multiple myofibrillar and metabolic proteins in female murine gastrocnemius muscle with $80 \%$ of transcripts higher in females, while Roth et al. [6] found differential transcription of roughly 200 genes in vastus lateralis muscle biopsies of adult men and women, $75 \%$ of which were higher in men, without a clear functional pattern. The inconsistency between the studies is likely due to procedural differences [5] or tissue. Regardless, mRNA levels are not always consistent with protein abundance [7] and cannot provide information regarding post-translational modifications, making it important to consider protein expression in addition to transcription. To our knowledge there has not been a proteomic study of exercise-naïve skeletal muscle that examines protein abundance and post-translational modifications in both genders.

We hypothesize that the strong gender dimorphism illustrated in the literature is due partly to metabolic challenge and gender-specific adaptation of the muscle tissue. Therefore, we do not expect to observe widespread or large differences in protein expression of exercise-naive mice. 


\section{MATERIALS AND METHODS}

Five male and five female exercise-naïve mice (C57BL/10ScSnJ 000476 +/+, Jackson Laboratories, 8-10 weeks old, bred on-site) were euthanized by $\mathrm{CO}_{2}$ inhalation and their biceps removed. Animal protocols were approved by the Smith College IACUC. Muscles were minced and homogenized in a denaturing urea-CHAPS buffer ( $8 \mathrm{M}$ urea, $50 \mathrm{mM}$ DTT, 4\% CHAPS, $0.2 \% \mathrm{pH} \mathrm{5-8}$ carrier ampholytes, $0.0002 \%$ Bromophenol Blue) and centrifuged at 15,600 rcf for $30 \mathrm{~min}$; supernate was acetone-precipitated twice [8] and the protein concentrations standardized using a modified Lowry protocol [9].

Protein samples ( $800 \mu \mathrm{g}$ total protein in urea-CHAPS buffer) were loaded onto $11 \mathrm{~cm}, \mathrm{pH}$ 5-8 IPG strips (Bio-Rad Labs) and focused 40,000 V-Hrs [10]. The IPG strips were equilibrated in a denaturing SDS buffer (6 M urea, $2 \%$ SDS, $0.05 \mathrm{M}$ Tris/ $\mathrm{HCl}, 20 \%$ glycerol) and alkylated [10], embedded onto $11 \mathrm{~cm}$ $10.5-14 \%$ Tris-HCl gels (Bio-Rad Labs), and electrophoresed at $120 \mathrm{~V}$. Gels were stained with Coomassie Brilliant Blue R-250.

Gels were imaged using QuantityOne software (v 4.6, Bio-Rad Labs; VersaDoc Scanner, Model 4000, Bio-Rad Labs) and cropped to $122.1 \mathrm{~mm} \times 71.3 \mathrm{~mm}$ size for uniformity. Images were loaded into a match set using PDQuest software (v 8.0.1, Build O55, Bio-Rad Labs). Large protein spots displaying multiple peaks (identified as the same protein by LC-MS/MS) were electronically combined into one spot, and streaks and speckles were removed. Gels were normalized using PDQuest's local regression model to correct for loading variation. Spot matching was performed automatically by PDQuest, with manual adjustments and removal of spots within the dye front and unresolved side columns. All spots with statistically significant differences in intensity between male and female subgroups ( $\mathrm{p}<0.05$ as measured by a Student's t-test) were excised from the gels using an ExQuest Spot Cutter (Bio-Rad Labs), and matched spots were pooled. Spots were digested with trypsin (In-Gel Tryptic Digest Kit, Pierce) and the samples de-salted with C-18 columns (Pierce).

Peptides were sequenced by liquid chromatography-coupled mass spectrometry (Finnigan LCQ Deca XP Max, Thermo Electron Corporation): $5 \mu \mathrm{l}$ of sample were injected onto a Pepswift monolithic PS-DVB column (Dionex Corp.) using the Nanospray I source (no waste injection), a flow rate of $400 \mathrm{nl} \mathrm{min}^{-1}$ at the tip, and elution over a 40 -minute $2-50 \%$ acetonitrile gradient with $0.2 \%$ formic acid. The MS1 scan was set between $400-1400 \mathrm{~m} / \mathrm{z}$, with the 3 most intense ion peaks isolated for MS2 sequencing with CID (dynamic exclusion enabled). Peptide results were analyzed via a Sequest mouse reference database search (BioWorks software, revision 3.3.1 SP1, Thermo-Fisher Scientific, Inc.), with a static alkylated cysteine modification and dynamic modifications for phosphorylation (serine, threonine, tyrosine), methylation (histidine), oxidation (methionine), ADP-ribosylation (arginine), and N-terminal acetylation. Tolerances were set at 2 AMU peptide tolerance and 1.00 fragment ions tolerance. Accepted proteins contained at least 2 peptides passing an XCorr vs 
Charge State filter (peptide filter, parameters $\mathrm{z}=1 / \mathrm{x}=1.50, \mathrm{z}=2 / \mathrm{x}=2.00$, $\mathrm{z}=3 / \mathrm{x}=2.50, \quad \mathrm{z}=4 / \mathrm{x}=3.00$ ) and a probability $\mathrm{p}<0.05$. Following protein identifications, proteins with an apparent molecular weight at least $5 \mathrm{kDa}$ lower than the monoisotopic weight accompanied by a poor sequence distribution of identified peptides were removed from the dataset as proteolytic fragments.

\section{RESULTS AND DISCUSSION}

As expected, the number of protein spots affected by gender in non-exercised, exercise-naïve mice was not large. Each edited gel resolved an average of 608 protein spots, with 85 spots showing significant differences between genders. Of the 66 spots successfully identified, 32 contained proteolytic fragments, and 3 contained myosin heavy polypeptide. The fragments and myosins were not quantified further, as we could not verify physiological significance for fragments nor determine isoform specificity for the myosins due to the peptide locations within homologous regions of the proteins. Twenty-nine protein spots containing 26 distinct proteins were quantified (Fig. 1, Tab. 1). Proteins of $\mathrm{M}_{\mathrm{r}}$ outside $15-110 \mathrm{kDa}$ or $\mathrm{pI}$ outside $4.5-8.0$ were not analyzed due to their poor resolution on 2-D gels. Highly hydrophobic proteins are rarely represented due to aqueous resuspensions and the use of C-18 columns.

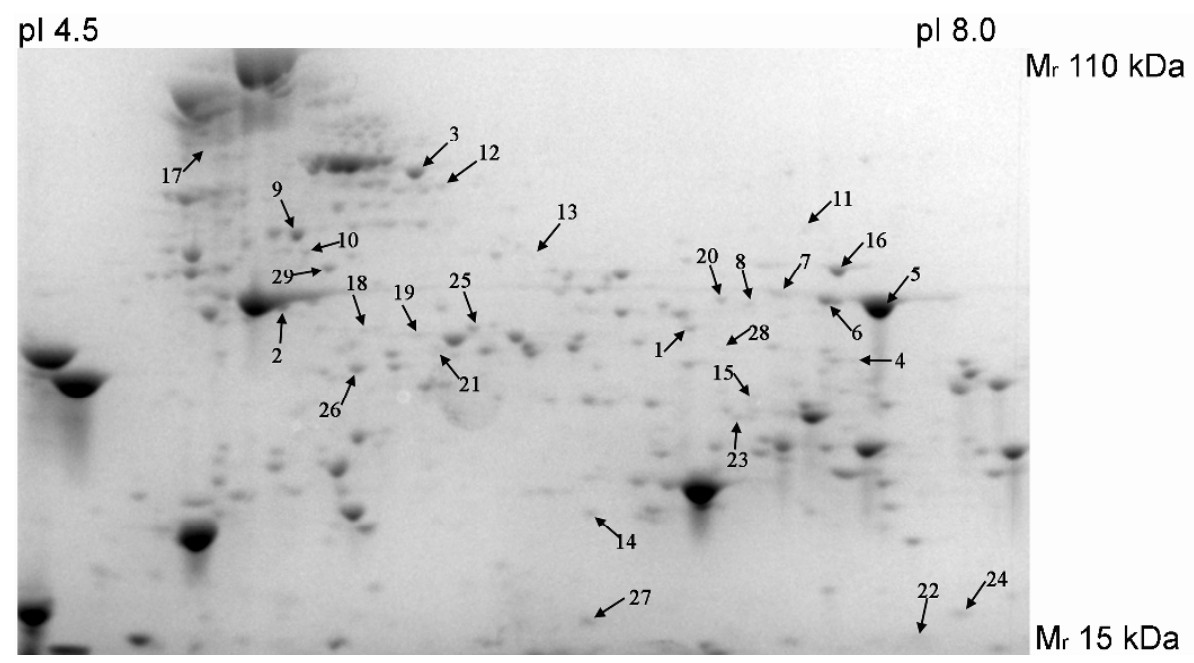

Fig. $1.11 \mathrm{~cm} \mathrm{pH} \mathrm{5-8} \mathrm{gel} \mathrm{of} \mathrm{exercise-naïve} \mathrm{female} \mathrm{murine} \mathrm{biceps} \mathrm{brachii.} \mathrm{M}_{\mathrm{r}}$ range is approximately $15-110 \mathrm{kDa}$. Numbers correspond to those in Tab. 1 .

\section{Quantification}

Twenty-four of the 29 protein spots quantified were less abundant in female mice, and the changes were significant but typically small (less than two-fold). The only proteins to show significantly greater abundances in females were GRP78; mitochondrial proteins myoglobin, and electron transferring 
flavoprotein alpha; and myofibrillar proteins alpha- 1 actin and desmin, both with isoelectric points indicating possible post-translational modification (Tab. 1).

The trend of decreased spot intensity in females can be explained by decreased abundance of the protein or post-translational modification. This trend is similar to the human vastus lateralis mRNA assay performed by Roth et al. [6] in which they found more than three fourths of transcripts up-regulated in males, though the specific proteins are not similar to those presented here. Of interest is that three protein fragments identified here were found to have increased transcription by Yoshioka et al. (ATP synthase, $\mathrm{H}+$ transporting mitochondrial F1 complex, beta subunit; Malate dehydrogenase 2, NAD [mitochondrial]; Aconitase 2, mitochondrial) [5], despite insignificant expression differences of the full-length protein between genders. This could indicate an increased turnover rate of these proteins in females when compared to males.

Tab.1. Proteins contained in spots demonstrating a statistically significant $(\mathrm{p}<0.05)$ abundance difference between genders, identified by LC-MS/MS. All proteins quantified showed $\mathrm{M}_{\mathrm{r}}$ within $5 \mathrm{kDa}$ of their calculated molecular weight; proteins with $\mathrm{M}_{\mathrm{r}}$ outside this range accompanied by a poor $\mathrm{N}-\mathrm{C}$ distribution of identified peptides were considered proteolytic fragments and are so noted. ${ }^{\mathrm{a}}$ The spot contains multiple proteins passing search criteria.

\begin{tabular}{|c|c|c|c|c|}
\hline Protein name & $\begin{array}{l}\text { Fold-change in } \\
\text { females, } p<0.05 \\
\text { (Label in Fig. 1) }\end{array}$ & $\begin{array}{l}\text { KOG } \\
\text { group }\end{array}$ & $\begin{array}{c}\text { Molecular } \\
\text { weight }(\mathrm{kDa}) \\
\text { Isoelectric } \\
\text { point }(\mathrm{pH})\end{array}$ & $\begin{array}{l}\text { Apparent } \\
\mathrm{M}_{\mathrm{r}}, \mathrm{pI}\end{array}$ \\
\hline $\begin{array}{l}\text { Acetyl-Coenzyme A acyltransferase } 2 \\
\text { (mitochondrial 3-oxoacyl-Coenzyme A } \\
\text { thiolase) }\end{array}$ & $-1.54(1)$ & I & $42,8.1$ & $41,6.2$ \\
\hline Aconitase 2 , mitochondrial & Fragment & $\mathrm{C}, \mathrm{E}$ & $85,7.8$ & $46,6.0$ \\
\hline Actin, alpha 1 & $+2.32(2)$ & Z & $42,5.1$ & $43,5.2$ \\
\hline Actin, beta, cytoplasmic & Fragment & Z & $42,5.2$ & $27,5.4$ \\
\hline Actin, gamma, cytoplasmic 1 & Fragment & Z & $42,5.2$ & $27,5.4$ \\
\hline Albumin, 1 & $-1.85(3)$ & I & $69,5.7$ & $69,5.7$ \\
\hline $\begin{array}{l}\text { Aldo-keto reductase family 1, member } \\
\text { B3 (aldose reductase) }\end{array}$ & $-2.27(4)$ & $\mathrm{R}$ & $36,6.8$ & $37,6.5$ \\
\hline Aldolase $1, \mathrm{~A}$ isoform & Fragment & G & $39,8.0$ & $28,6.3$ \\
\hline $\begin{array}{l}\text { ATP synthase, } \mathrm{H}+\text { transporting } \\
\text { mitochondrial F1 complex, beta subunit }\end{array}$ & Fragment & $\mathrm{C}$ & $56,5.1$ & $29,4.9$ \\
\hline Citrate synthase & Fragment & $\mathrm{C}$ & $52,8.7$ & $28,6.3$ \\
\hline Creatine kinase, muscle (CK) & $-2.08(5)$ & $\mathrm{C}$ & $43,6.6$ & $43,6.6$ \\
\hline Creatine kinase, muscle $(\mathrm{pCK})^{\mathrm{a}}$ & $-1.52(6)$ & $\mathrm{C}$ & 43. 6.6 & $43,6.4$ \\
\hline Creatine kinase, muscle (ppCK) & $-1.61(7)$ & $\mathrm{C}$ & $43,6.6$ & $43,6.3$ \\
\hline Creatine kinase, muscle & $-1.89(8)$ & $\mathrm{C}$ & $43,6.6$ & $43,6.3$ \\
\hline Desmin (ADP-Ribosylated) & $-1.67(9)$ & $\mathrm{Z}$ & $53,5.1$ & $55,5.2$ \\
\hline
\end{tabular}




\begin{tabular}{|c|c|c|c|c|}
\hline Protein name & $\begin{array}{c}\text { Fold-change in } \\
\text { females, } \mathrm{p}<0.05 \\
\text { (Label in Fig. 1) }\end{array}$ & $\begin{array}{l}\text { KOG } \\
\text { group }\end{array}$ & $\begin{array}{c}\text { Molecular } \\
\text { weight }(\mathrm{kDa}), \\
\text { Isoelectric } \\
\text { point }(\mathrm{pH})\end{array}$ & $\begin{array}{l}\text { Apparent } \\
\mathrm{M}_{\mathrm{r}}, \mathrm{pI}\end{array}$ \\
\hline Desmin & $+1.66(10)$ & Z & $53,5.1$ & $52,5.3$ \\
\hline $\begin{array}{l}\text { Dihydrolipoamide dehydrogenase (p) } \\
\text { (PDH E3) }\end{array}$ & $-2.22(11)$ & $\mathrm{C}$ & $54,7.8$ & $57,6.4$ \\
\hline $\begin{array}{l}\text { Dihydrolipoamide S-acetyltransferase }{ }^{a} \\
\text { (PDH E2) }\end{array}$ & $-2.22(12)$ & $\mathrm{C}$ & $68,8.7$ & $65,5.7$ \\
\hline Dihydrolipoamide S-succinyltransferase & $-5.88(13)$ & $\mathrm{C}$ & $49,9.3$ & $51,5.9$ \\
\hline DJ-1 protein & $-2.00(14)$ & $\mathrm{V}$ & $20,6.4$ & $23,6.0$ \\
\hline $\begin{array}{l}\text { Electron transferring flavoprotein, alpha } \\
\text { polypeptide }\end{array}$ & $+1.51(15)$ & $\mathrm{C}$ & $35,8.2$ & $33,6.3$ \\
\hline $\begin{array}{l}\text { Electron transferring flavoprotein, } \\
\text { dehydrogenase }\end{array}$ & Fragment & $\mathrm{C}$ & $68,7.3$ & $39,6.9$ \\
\hline Enolase 3, beta & $-2.44(16)$ & G & $47,6.8$ & $47,6.5$ \\
\hline $\begin{array}{l}\text { Heat shock } 70 \mathrm{kD} \text { protein } 5 \text {, glucose- } \\
\text { regulated protein (GRP78) (ER-Hsp70) }\end{array}$ & $+5.80(17)$ & $\mathrm{O}$ & $72,4.9$ & $72,4.9$ \\
\hline $\begin{array}{l}\text { Isocitrate dehydrogenase } 3 \text { (NAD+) } \\
\text { alpha }\end{array}$ & $-1.75(18)$ & $\mathrm{C}$ & $40,6.3$ & $40,5.5$ \\
\hline $\begin{array}{l}\text { Isocitrate dehydrogenase } 3(\mathrm{NAD}+) \\
\text { alpha }\end{array}$ & $-1.64(19)$ & $\mathrm{C}$ & $40,6.3$ & $40,5.7$ \\
\hline Isocitrate dehydrogenase 3 , beta subunit & Fragment & $\mathrm{E}$ & $42,8.8$ & $32,6.2$ \\
\hline Isovaleryl coenzyme A dehydrogenase & $-1.39(20)$ & $\mathrm{E}, \mathrm{I}$ & $46,8.3$ & $43,6.2$ \\
\hline Lactate dehydrogenase 2 , B chain & $-2.33(21)$ & $\mathrm{C}$ & $37,5.7$ & $38,5.7$ \\
\hline $\begin{array}{l}\text { Malate dehydrogenase 2, NAD } \\
\text { (mitochondrial) }\end{array}$ & Fragment & $\mathrm{C}$ & $36,8.8$ & $28,6.3$ \\
\hline Myoglobin & $+3.94(22)$ & $\mathrm{C}$ & $17,7.6$ & $15,7.0$ \\
\hline Myozenin 1 & $-1.43(23)$ & $\mathrm{C}$ & $31,9.1$ & $31,6.3$ \\
\hline Nucleoside-diphosphate kinase 2 & $-1.75(24)$ & $\mathrm{F}$ & $17,7.4$ & $17,7.3$ \\
\hline Phosphoglycerate kinase 1 & $-1.59(25)$ & G & $44,7.6$ & $41,5.8$ \\
\hline $\begin{array}{l}\text { Pyruvate dehydrogenase (lipoamide) } \\
\text { beta }\end{array}$ & $-1.79(26)$ & $\mathrm{C}$ & $39,6.4$ & $36,5.5$ \\
\hline Pyruvate dehydrogenase E1 alpha $1^{\text {a }}$ & $-1.52(6)$ & $\mathrm{C}$ & $43,8.1$ & $43,6.4$ \\
\hline Pyruvate kinase 3 & Fragment & G & $58,7.2$ & $46,6.0$ \\
\hline Superoxide dismutase 1 , soluble & $-2.00(27)$ & $\mathrm{P}$ & $16,6.0$ & $16,6.0$ \\
\hline Titin (predicted) & Fragment & $\mathrm{Z}$ & $2222,6.7$ & $43,6.3$ \\
\hline $\begin{array}{l}\text { Transformation related protein } 63 \\
(\text { ppp63) }\end{array}$ & $-2.22(12)$ & $\mathrm{K}$ & $66,7.5$ & $65,5.7$ \\
\hline Troponin T3, skeletal, fast & $-2.56(28)$ & $\mathrm{Z}$ & $29,9.5$ & $38,6.2$ \\
\hline $\begin{array}{l}\text { Ubiquinol-cytochrome c reductase core } \\
\text { protein } 1\end{array}$ & $-1.82(29)$ & $\mathrm{C}$ & $53,5.8$ & $48,5.4$ \\
\hline
\end{tabular}




\section{General protein localization and ontological grouping}

In accordance with the literature, metabolic proteins displayed the most striking gender dimorphism in this study. The majority of identified proteins were involved in metabolism, with representation among cytoskeletal and stress proteins as well (Fig. 2A). Localization of the identified proteins was distributed between the mitochondrial, sarcomeric and cytoplasmic compartments (Fig. 2B). No gross compartmentalization differences between genders were observed. Mitochondrial proteins did not comprise more than a third of total proteins identified, and did not show a blanket expression increase in one gender, leaving no evidence of a greater mitochondrial concentration in females. While females are thought to have a greater mitochondrial density than males [11], these studies use muscle tissue that has been metabolically challenged.

A

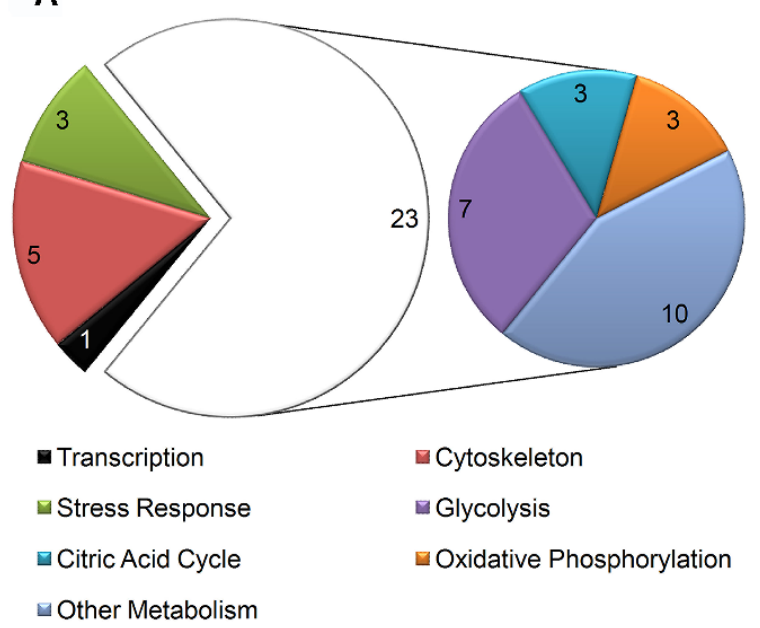

B

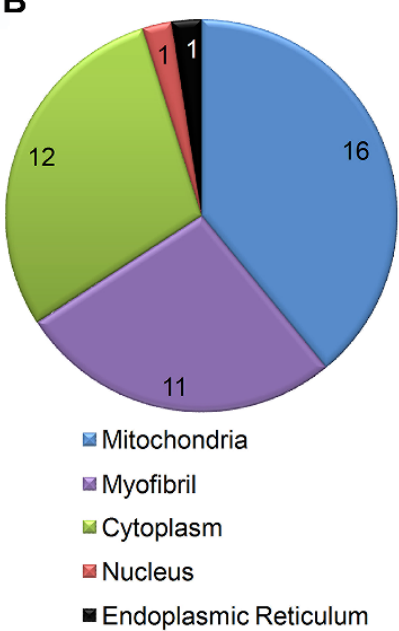

Fig. 2. Full-length proteins found within spots significantly different between exercisenaïve male and female murine biceps brachii. A single protein found in two spots with different isoelectric points is treated as two separate proteins. A - Breakdown of identified proteins according to gross function. The majority of these identified proteins have metabolic functions, and were further divided according to major metabolic pathways. B - Breakdown of identified proteins according to localization within the cell. While metabolic proteins are better represented than other functional groups, there is not a clear preference for localization of these proteins.

\section{Non-metabolic proteins}

Females showed decreased abundance of Troponin T3 fast (Tab. 1), which could indicate a greater proportion of oxidative fiber types. This pattern is confirmed by the significantly decreased Troponin T3 fast transcription observed in female C57/BL6 murine gastrocnemius muscle by Yoshioka et al. [5]. A greater proportion of oxidative fibers is consistent with the increased expression found for myoglobin in our female mice. 
The intermediate filament protein desmin showed a pattern of spots consistent with post-translational modification, with two spots showing a change in expression (one spot increased 1.7-fold; the other decreased by the same amount, with the females favoring the spot with a more acidic $\mathrm{pI}$ and slightly greater $\mathrm{M}_{\mathrm{r}}$ ). It is known that site-specific desmin phosphorylation affects filament assembly and disassembly [12] and ADP-ribosylation of arginine inhibits desmin filament assembly [13]. The desmin spot favored by female mice was confirmed to have an ADP-ribosylation.

\section{Metabolic proteins}

The difference in mitochondrial proteins is interesting given the exercise-naïve condition of the mice; while the gender dimorphism of the metabolic response to exercise could be exacerbated by training; there is an underlying physiological difference in the baseline expression of metabolic proteins. Every glycolytic protein identified was less abundant in females, which could be consistent with either a greater reliance on lipid oxidation in females or a fiber type gender dimorphism. Of the glycolytic enzymes quantified, females demonstrated lower abundance of lactate dehydrogenase, enolase 3 beta, phosphoglycerate kinase 1 and four enzymes of the pyruvate dehydrogenase complex: pyruvate dehydrogenase E1 alpha 1, pyruvate dehydrogenase (lipoamide) beta, dihydrolipoamide s-acetyltransferase and dihydrolipoamide dehydrogenase. Conversely, two of three proteins associated with oxidative phosphorylation showed increased expression in females: myoglobin and electron transferring flavoprotein alpha polypeptide. Few proteins specific to lipid or amino acid metabolism were identified.

Also of interest is the decreased expression of creatine kinase and all its phosphoisoforms observed here in females. Both female animals [14] and women [15] have lower resting and exercising serum CK levels than their male counterparts. Serum CK levels are used as an indirect measurement of membrane permeability associated with muscle damage, but have questionable correlation with morphological findings [16]. A decreased intracellular abundance of MM-CK in females could result in the decreased serum CK activity observed in females, and would be consistent with the questionable relationship between serum CK activity and myofibrillar disruption following damaging exercise, especially between genders.

\section{Hormone influence}

Absent from the significantly different proteins are known hormonally-regulated proteins such as hormone-sensitive lipase, sex steroid receptors or GLUT4. Comparisons of gender dimorphism in metabolic gene transcription of human skeletal muscle tissue and skeletal muscle cell cultures indicate that substrate utilization differences stem from systemic stimuli rather than intrinsic cellular or sub-cellular differences [17]. Estrogen especially has been linked with metabolism: $17-\beta$-estradiol supplementation in males increases the rate of fatty acid oxidation while decreasing carbohydrate and leucine oxidation [18], 
estrogen receptors can regulate the expression of GLUT4 on the plasma membrane [19], and substrate utilization in women during exercise is influenced by the phase of the menstrual cycle [20]. Because estrogen levels vary throughout the four-day estrous cycle in mice, and our mice were not matched for estrous cycle phase, there might be a statistical bias against heavily sex hormone-regulated expression changes due to variation within the female group.

\section{CONCLUSION}

We observed gender dimorphism in the proteome maps of exercise-naïve, agematched male and female mice, primarily in metabolic proteins of the main energy pathways. Glycolytic enzymes and creatine kinase were less abundant in females.

Acknowledgements. This work was supported by National Science Foundation 0420971; the Smith College Blakeslee, Wilens and Holmes funds; and Howard Hughes Medical Institute.

\section{REFERENCES}

1. Tarnopolsky, M.A. Gender differences in carbohydrate loading are related to energy intake. J. Appl. Physiol. 91 (2001) 225-230.

2. Phillips, S.M., Atkinson, S.A., Tarnopolsky, M.A. and MacDougall, J.D. Gender differences in leucine kinetics and nitrogen balance in endurance athletes. J. Appl. Physiol. 75 (1993) 2134-2141.

3. Tarnopolsky, M.A. Sex differences in exercise metabolism and the role of $17-\beta$ estradiol. Med. Sci. Sports Exerc. 40 (2008) 648-654.

4. Metskas, L.A., Kulp, M. and Scordilis, S.P. Differential proteome profiling analysis of male and female murine skeletal muscle following a repeat bout of exercise. FASEB J. 23 (2009): 601.4.

5. Yoshioka, M., Boivin, A., Bolduc, C. and St-Amand, J. Gender difference of androgen actions on skeletal muscle transcriptome. J. Mol. Endocrinol. $\underline{39}$ (2007) 119-133.

6. Roth, S.M., Ferrell, R.E., Peters, D.G., Metter, E.J., Hurley, B.F. and Rogers, M.A. Influence of age, sex, and strength training on human muscle gene expression determined by microarray. Physiol. Genomics 10 (2002) 181-190.

7. Thompson, H.S. When stress is good: exercise and stress protein responses in mice and humans. PhD dissertation, University of Massachusetts Amherst, Amherst, Massachusetts, (2003).

8. Thompson, H.S, Clarkson, P.M., and Scordilis, S.P. The repeated bout effect and heat shock proteins: intramuscular HSP27 and HSP70 expression following two bouts of eccentric exercise in humans. Acta Physiol. Scand. $\underline{174}$ (2002) 47-56. 
9. Lowry, O.H., Rosenburg, N.J., Farr, A.L. and Randall, R.J. Protein measurement with the Folin phenol reagent. J. Biol. Chem. 193 (1951) 265-275.

10. Bio-Rad Laboratories. ReadyPrep 2-D Starter Kit Instruction Manual. Cat. No. 163-2105.

11. Colom, B., Alcolea, M.P., Valle, A., Oliver, J., Roca, P. and Garcia-Palmer, F.J. Skeletal muscle of female rats exhibit higher mitochondrial mass and oxidative-phosphorylative capacities compared to males. Cell. Physiol. Biochem. 19 (2007) 205-212.

12. Izawa, I. and Inagaki, M. Regulatory mechanisms and functions of intermediate filaments: a study using site- and phosphorylation state-specific antibodies. Cancer Sci. 93 (2006) 167-174.

13. Zhou, H., Huiatt, T.W., Robson, R.M., Sernett, S.W., and D.J. Graves. Characterization of ADP-ribosylation sites on desmin and restoration of desmin intermediate filament assembly by de-ADP-ribosylation. Arch. Biochem. Biophys. 334 (1996) 214-222.

14. Amelink, G.J., Kamp, H.H. and Bär, P.R. Creatine kinase isoenzyme profiles after exercise in the rat: sex-linked differences in leakage of CKMM. Pflügers Arch. $\underline{412}$ (1988) 417-421.

15. Norton, J.P., Clarkson, P.M., Graves, J.E., Litchfield, P.L. and Kirwan, J. Serum creatine kinase activity and body composition in males and females. Hum. Biol. 57 (1985) 591-598.

16. Kendall, B. and Eston, R. Exercise-induced muscle damage and the potential protective role of estrogen. Sports Med. 32 (2002) 103-123.

17. Rune, A., Salehzadeh, F., Szekeres, F., Kühn, I., Osler, M.E. and Al-Khalili, L. Evidence against a sexual dimorphism in glucose and fatty acid metabolism in skeletal muscle cultures from age-matched men and postmenopausal women. Acta Physiol. 197 (2009) 207-215.

18. Hamadeh, M.J., Devries, M.C. and Tarnopolsky, M.A. Estrogen supplementation reduces whole body leucine and carbohydrate oxidation and increases lipid oxidation in men during endurance exercise. J. Clin. Endocrinol. Metab. 90 (2005) 3592-3599.

19. Barros, R.P.A., Machado, U.F., Warner, M. and Gustafsson, J.A. Muscle GLUT4 regulation by estrogen receptors ER $\beta$ and ER $\alpha$. PNAS 103 (2006) 1605-1608.

20. Devries, M.C., Hamadeh, M.J., Phillips, S.M. and Tarnopolsky, M.A. Menstrual cycle phase and sex influence muscle glycogen utilization and glucose turnover during moderate-intensity endurance exercise. Am. J. Physiol. Regulatory Integrative Comp. Physiol. 291 (2006) 1120-1128. 